\title{
Albert Wojciech Adamkiewicz (1850-1921): unsung hero behind the eponymic artery
}

\author{
Sunil Manjila, M.Ch., Nivin Haroon, M.B.B.S., Brandon Parker, B.A., \\ Andrew R. Xavier, M.D., Murali Guthikonda, M.D., and Setti S. Rengachary, M.D. \\ Department of Neurosurgery and Division of Endovascular Neurosurgery, Wayne State University School of \\ Medicine and Detroit Medical Center, Detroit, Michigan
}

\begin{abstract}
The artery of Adamkiewicz is an important radiculomedullary artery supplying the spinal cord, especially the lumbar enlargement. Anatomical knowledge of this artery is important for avoiding serious neurological complications during surgery performed in this region - for neurosurgeons and interventional radiologists treating intramedullary tumors and spinal arteriovenous malformations, traumatologists performing spinal fusions, thoracic surgeons treating aortic aneurysms, and urologists and pediatric surgeons conducting retroperitoneal dissections. However, the biography of the talented Polish pathologist Albert Adamkiewicz, after whom the landmark artery is named, has not been described adequately in the existing neurosurgical literature. The authors bring to light the historical perspective of the eponymic artery and provide a recapitulation of other significant contributions made by Adamkiewicz, mostly involving the nervous system. His research papers on the histology of neuronal tissues and neurodegenerative diseases had high scientific merit, but the discovery of the anticancer antitoxin "cancroin" and his postulation of a cancer-causing parasite he named "Coccidium sarcolytus" met with harsh criticism and eventually led to his ill fame. The biography is supplemented with a brief overview of the important surgical implications of the artery of Adamkiewicz. (DOI: 10.3171/FOC.2009.26.1.E2).
\end{abstract}

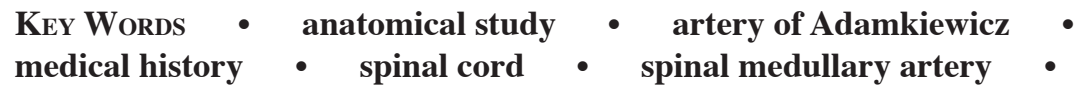

$\mathrm{T}$ HE artery of Adamkiewicz is the only radiculomedullary artery that supplies the thoracolumbar region of the human spinal cord..$^{28,30,31}$ This artery has immense anatomical and clinical significance and continues to stimulate researchers of neurovascular anatomy. However, there is a definite paucity of neurosurgical literature describing the life history of Albert Wojciech Adamkiewicz or citation of his work and its influence on modern medicine (Fig. 1). This eponymic artery remains one of the most significant of his various contributions to medical science. His tenure at Jagiellonian University attested to his role as an accomplished researcher, even though specked with failures and criticisms from his own medical fraternity. The artery named after him gained clinical significance as a surgical landmark over the years.

\section{The Making of a Neuropathologist}

Albert Wojciech Adamkiewicz, born August 11, 1850 , in the Duchy of Poznan, Zerków (Western Poland),

Abbreviations used in this paper: ASA = anterior spinal artery; $\mathrm{MEP}=$ motor evoked potential . was the son of Adolf Adamkiewicz, who was a smalltown doctor. From his high school days he had shown remarkable interest in biological science and medicine. In 1868, he graduated from high school with honors, and the note on his high school report read, "he excelled in all subjects and possesses strong determination to achieve his life goals." At the age of 18 years, he went to Königsberg in East Prussia (now Kaliningrad, Russia) to study medicine. After 6 months, he moved to the University of Breslau (now the University of Wroclaw) in southwestern Poland, where he was assigned to work as a student assistant to Professor Rudolf Peter Heinrich (1834-1897), who was well known for his work on muscle and nerve physiology. ${ }^{11,25}$ After 2 years, he was drafted into military service during the Franco-Prussian War of 1870. By 1871 the war was over, and he resumed his studies at Julius-Maximilians-Universität Würzburg (University of Würzburg) in Bavaria, a reputable university established in 1402. His hard work earned him the position of student assistant in the renowned Department of Anatomical Pathology, headed by Professor Friedrich D. von Recklinghausen (1833-1910), an eminent professor known for his lectures. ${ }^{4}$ In 1872 Albert won the first prize granted by the medical faculty of Würzburg, for the paper "Die 


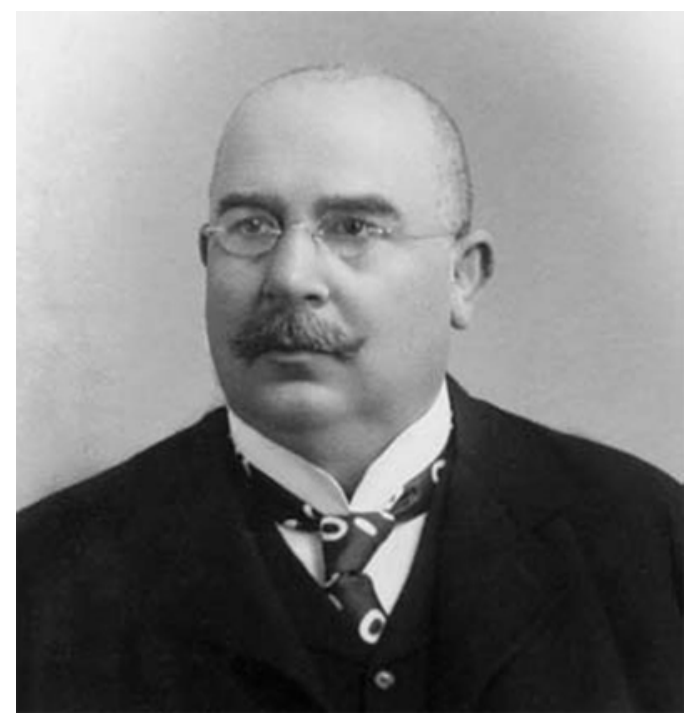

FIG. 1. Photograph of Albert Wojcieh Adamkiewicz (1850-1921).

mechanischen Blutstillungsmittel," in which he dealt with the mechanical methods of phlebotomy. This paper was subsequently published in the esteemed periodical Langenbecks Archives. The paper also earned him the title of Doctor of Medicine, Surgery, and Obstetrics. In 1873 he returned to Breslau, where he took the state examination and obtained his medical diploma. ${ }^{11,25}$

Soon after graduation, Adamkiewicz was placed as the assistant to Professor Wilhelm von Wittich (1821-1884) in the Department of Physiology and Clinical Medicine at the University of Königsberg. After 2 years of service and active research, he was promoted to Director of Clinical Laboratory in the Department of Clinical Medicine. Here he worked alongside Bernhard Naunyn (1839-1935), who conducted research in experimental pathology, especially the xenobiotic metabolism. Adamkiewicz, a promising and energetic young physician, was subsequently offered the post of senior physician in the Department of Neurology at the Charité Hospital in Berlin by Carl Friedrich Otto Westphal (1833-1890), a prominent neuropathologist remembered for his work on pseudosclerosis (hepatolenticular degeneration), Erb-Westphal syndrome, and Edinger-Westphal nucleus of cranial nerve III. The association with Westphal inspired Adamkiewicz to pursue the study of the CNS. He submitted his second dissertation (habilitationsschrift) during this time, which earned him the title of Privatdozent (associate professor). ${ }^{26} \mathrm{With}$ these stimulating experiences from several institutions, Adamkiewicz matured into an astute researcher and efficient teacher. His classes were garnished with innovative experiments, and his popularity grew as an academician as well as a researcher. This newly earned fame brought him to the doorstep of Jagiellonian University Collegium Medicum in Kraków, Poland. ${ }^{11,25}$

\section{Adamkiewicz at Jagiellonian University}

Jagiellonian University, founded in 1364, was the second university to be established in Central Europe af-

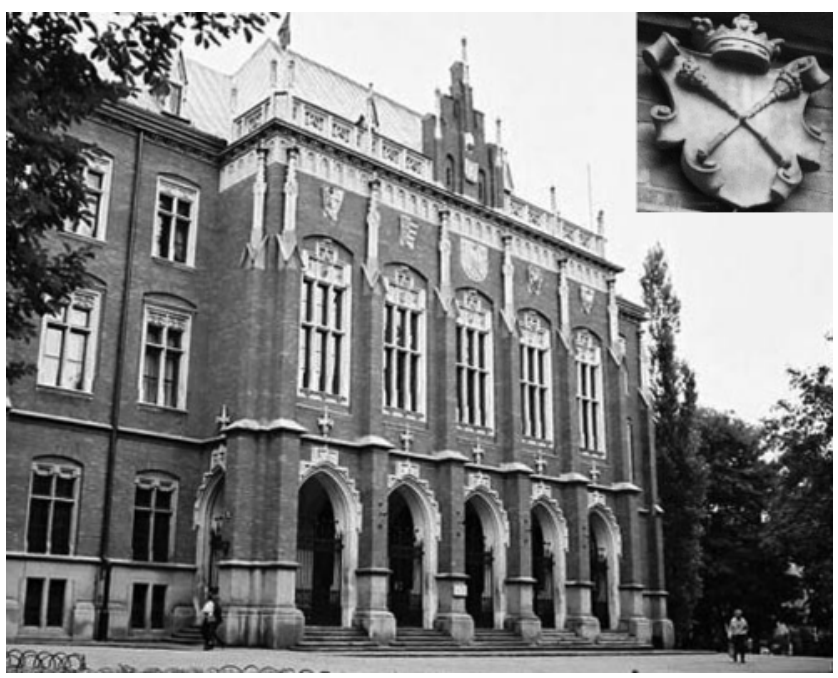

FIG. 2. Jagiellonian University in Krakow, Poland. Inset: Photograph of coat of arms of Jagiellonian University.

ter the one in Prague (Fig. 2). The university saw many ups and downs after its establishment because of constant wars and political divisions. It was during the second golden era of the institution that Albert Adamkiewicz joined on as a professor in the Department of General and Experimental Pathology. Interestingly, Adamkiewicz had his triumph as well as his downfall as a researcher at Jagiellonian University. His initial period at the university was perhaps the most productive and outstanding time of his career. During this phase, he authored more than 43 papers and 10 monographs. At the height of his career, he was well recognized by his contemporaries, his works were featured in well-known journals, and he received several awards and distinctions. ${ }^{37}$ His well-known works included the study of the vasculature of the spinal cord and medulla oblongata and the staining method for and the histology of nervous tissues. Today he is most remembered for the eponymic artery, as well as related works in the area of spinal cord vascularization. His papers were written in various languages including Polish, French, German, and Latin. He was part of various scientific bodies and societies such as the prestigious French Société de Biologie and the German Anatomical Society of Leipzig. ${ }^{25}$

The glory of his research career was not to last long, however. At the pinnacle of his professional life, his fame and reputation were severely damaged by his claims of the discovery of and early publications on a cancer parasite, Coccidium sarcolytus. Thought to be under the influence of studies conducted by German bacteriologist Robert Koch, he proposed a cancer treatment with the anticancer toxin he called "cancroin." His findings triggered a controversy, and the university faculty became highly critical of his thesis and its hasty publication. There were also sharp criticisms regarding the lack of originality in his works. Given the antagonism he faced, he left Jagiellonian University in 1892 and moved to Vienna to work with his friend and orthopedic surgeon Professor Eduard Albert. Adamkiewicz had been a full professor and chairperson of his department at the early age of 30 years; however, 


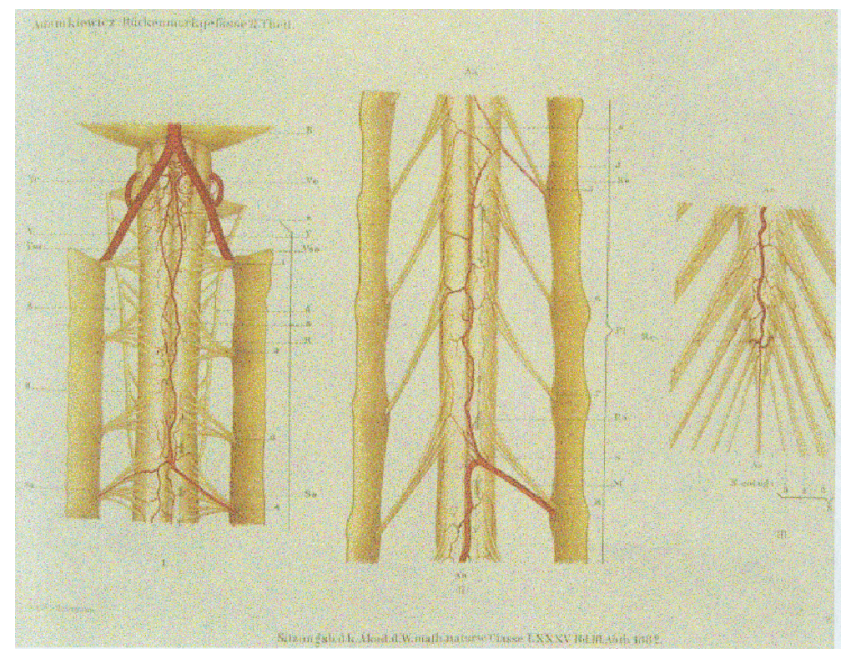

FIG. 3. Drawing obtained from an original article by Adamkiewicz published in 1881-1882, showing arterial vasculature of the spinal cord and the bidirectional flow of blood in spinal cord vasculature. .

he ended up taking this long sabbatical, approved by the Ministry of Health. ${ }^{26}$ In Vienna, he found favorable conditions to pursue his research on "cancroin," but his attempts were met with repeated failures on testing the serum. A decline in his health, failures in his work, and the loss of support from the scientific body together played key roles in his decision to temporarily retire from active research. He spent the rest of his career as a floor physician in the Rothschild Hospital in Vienna. While working as head of the ward there, he continued to publish clinical case reports and observations. In 1900, Adamkiewicz republished his experimental results on ganglionic neurons. He died in Vienna on October 31, 1921.

\section{Academic Works of Adamkiewicz}

Albert Adamkiewicz started his research primarily with the study of the mechanical methods of phlebotomy, work submitted for his first dissertation..$^{11,25}$ Soon thereafter, his preference shifted to CNS physiology and its pathological conditions. His research in pathology included the study of changes in brain tissue after compression and an innovative staining method to differentiate structures within the nervous tissue. At the 1884 meeting of the Vienna Academy of Sciences, he described the method of double staining in which he used gentian violet to stain the gray matter of the nervous tissue violet, whereas the rest of the parts, including the neuroglia, septum, and spinal leptomeninges, took up a blue color. Adamkiewicz also experimented with other stains such as methylene blue and safranine, which were used in the study of the spinal cord and medulla. ${ }^{30}$

Another of his important contributions to experimental medical research was the discovery of a quantitative colorimetric reaction to detect proteins. This reaction came to be known as the Adamkiewicz reaction and is based on the presence of the amino acid tryptophan in proteins, which form colored complexes after reacting with glyoxalic acid. A solution of protein and glyoxalic acid is mixed with concentrated sulfuric acid, and a redviolet ring appears at the interface of these components. Yet another major clinicopathological work of his included the observation that the degeneration of the posterior medial cord presents with atonic paralysis, whereas the degeneration of the lateral cords leads to pathological muscular tone.

In 1889 he conducted a significant descriptive study on progressive unilateral cranial nerve palsy. Additional studies on the same disease entity were performed later in 1927, and the condition was described as the Garcin hemibasal syndrome, which involved the unilateral paralysis of almost all cranial nerves in cases of tumors of the nasopharynx and skull base without affecting the brain itself. This condition occurs in one-half of the skull base and gradually worsens; fortunately, this is a rare disease.

Adamkiewicz conducted studies on the degenerative changes in the spinal cord in tabes dorsalis, which led to the study of spinal cord vascularization. The pioneering and most well-known of his studies was done in the field of blood supply to the spinal cord, and his data were published in 2 parts: "Die Blutgefasse des menschlichen Ruckenmarkes-die gefasse der Ruckenmarksubstanz" in 1881 and "Die Gefasse der ruckenmarksoberflache" in 1882. This study attested to the varied experience he had gained from different fields, including physiology and pathology. He applied a special method of preparing vascular preparations by using Teichmann mass, which consisted of ammonia, zinc white, linseed oil, mercury sulfate, or carmine sediment for the red color of the arteries and Prussian blue for the veins. ${ }^{30} \mathrm{He}$ found the "magnus ramus radicularis anterior" or "arteria magna spinalis," now widely known as the "artery of Adamkiewicz" (Fig. 3). Other names for the artery are the "great anterior medullary artery," "great radicular artery of Adamkiewicz," "great anterior segmental medullary artery," "great anterior radiculomedullary artery," and "artery of the lumbar enlargement." Adamkiewicz had skillfully demonstrated the variable origin, consistent morphology, and constant course of this radiculomedullary artery.

Adamkiewicz suggested 3 sectors of vascular supply to the spinal cord rather than the segmental supply that had been believed to exist in earlier days. He also described the complex anastomosing network of arteries surrounding the spinal cord, which he called "vasocorona" (vascular crown). The majority of anastomoses were described in relation to the ASA. In his famous monograph he mentioned the terminal end of the descending branch of the artery, which he called the "crus vasculosa." He also attempted to describe the venous network, which was subsequently characterized as complex and difficult to interpret. He also noted the variable density of microvasculature within the spinal cord: the gray matter was more densely vascularized than the white matter, and the vasculature in the spinal and lumbar areas was more dense than that in the rest of the segments of the spinal cord. The physiology of blood flow was the other significant observation made regarding blood supply of the spinal cord. He described the bidirectional flow within the spinal cord arterial system-blood flowing upward in 


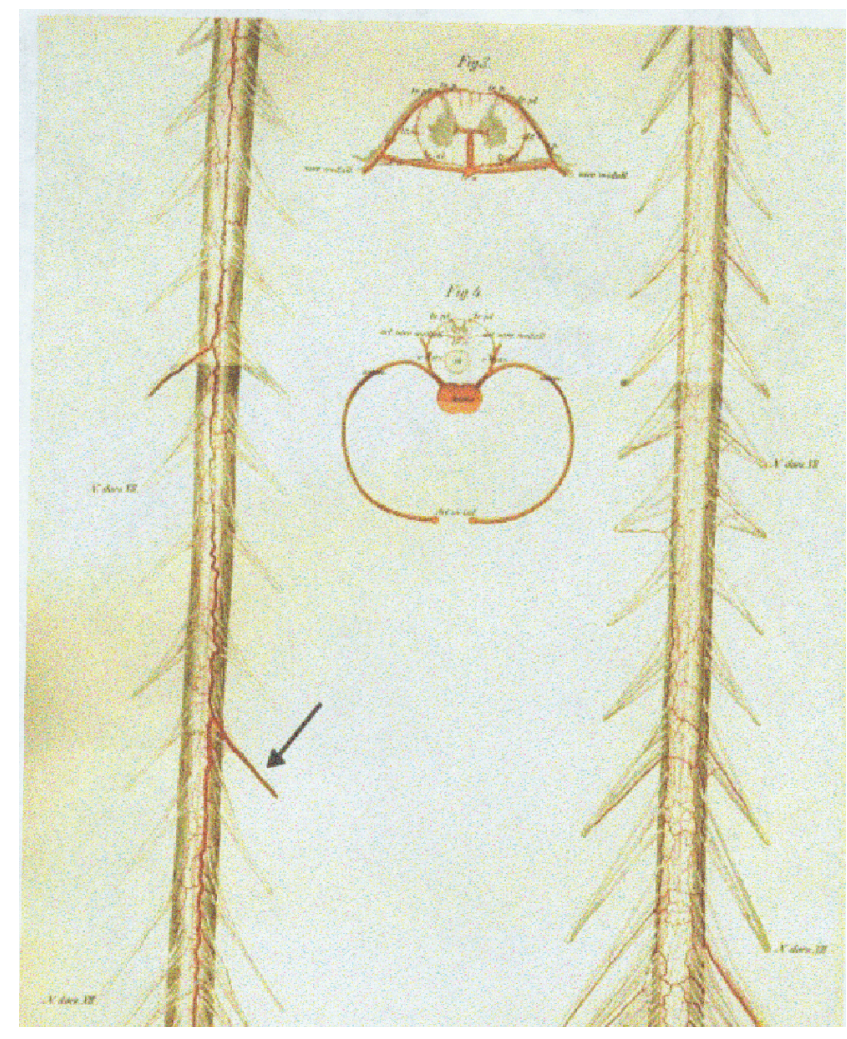

FIG. 4. Drawing showing the arterial supply of the spinal cord as depicted by Kadyi in 1888. Arrow indicates the great radicular artery.

the ascending arteries and downward in the descending arteries. He observed that within the spinal cord, blood usually flows toward the gray matter. He also noted that in pathological states this trend is disturbed, and this phenomenon was demonstrated in the thoracic segments. ${ }^{30}$

When discussing the study on vasculature of the spinal cord, it is imperative to mention the work of von Haller and Henryk Kadyi. Adamkiewicz had derived encouragement and inspiration from the initial works of von Haller (1754), who described the nonsegmental and asymmetrical blood supply of the spinal cord. Kadyi, on the other hand, was a contemporary of Adamkiewicz who worked as an assistant in Teichmann's anatomy department, researching the same area of spinal vasculature. He published the monograph "On the blood vessels of the spinal cord" later in 1888 , but this paper was more focused on the morphology of the vascular system than on the physiological descriptions of Adamkiewicz. In his monograph, Kadyi criticized Adamkiewicz's work:

Thus, the question is not whether this or any other area of the spinal cord could be found to be worse or more sparingly vascularized, as the peripheral branches arise from the same anastomotic chains. At the same time, it makes no difference for the tissue alimentation whether the arterial trunks feeding these chains in the first place arise nearby the roots of nerves derived from the area, or a few, and even a dozen or so nerves higher or lower. These morphological relations can be interesting, but physiologically, for the spinal cord alimentation, they are of no significance. The above remark would be quite unnecessary, if it were not for Adamkiewicz's erroneous statement that the thoracic segment of the spinal cord was, as far as the vascularization was concerned, discriminated, from which Adamkiewicz drew far-reaching conclusions that certainly must be wrong. ${ }^{31}$

Despite his criticisms, Kadyi mentioned in the same monograph

...that the region of the beginning of upper and middle thoracic nerves up to the IXth usually receives two, at most three, anterior radicular arteries. Sometimes in this region only small and scarce (1-2) arterioles are found, and at times there are no arterioles at all. In the region where the nerves from the IXth thoracic to the IIIrd lumbar nerve arise, the last from the bottom but still the strongest anterior radicular artery goes towards the spinal cord, and it always exceeds all other medullary arteries in its size. It can be termed "arteria radicalis magna."

Kadyi had agreed with the observations of Adamkiewicz and had also pointed toward a left-sided origin of the artery (Fig. 4). Later (1908), Tanon suggested naming the arteries that feed the spinal cord "radiculomedullary arteries." ${ }^{34}$ Ninety years later, the Federative Committee on Anatomical Terminology named the artery of Adamkiewicz the "segmental medullary artery." ${ }^{26}$ Even though the nomenclature changed, the description of this radiculomedullary artery by Adamkiewicz remains a cornerstone in understanding the spinal cord vasculature.

\section{Anticancer Research and Controversies}

The controversial works of Adamkiewicz include studies on carcinogenesis and its treatment. According to his theory, cancer displays 2 pathognomonic features of chronic infectious diseases: primary focus and metastases. He did not approve of the Cohnheim theory of epithelial origin and concluded that the greatest differences between cancer and epithelial cells were in their morphology and physiology. He proposed the presence of cancer-causing parasite Coccidium sarcolytus. Even though these organisms did not show a direct causal relationship, their presence arguably was proven by the discovery of the cancer antitoxin he called "cancroin." He used the brain of a rabbit to develop fresh cancerous material. He demonstrated that cancer cells move out of their clusters, migrate into fissures of the brain, consume brain material, and metastasize. He also asserted that cancer poison is formed within the cancer cells, and he called the cancer cell itself the parasite of cancer. He stated that the anticancer toxin had properties similar to neurine (vinyl-trimethyl-ammonium hydroxide) and possessed anodyne and deodorizing qualities. He established this fact by injecting neurine into a lowerlid cancer, which reacted by swelling and clearing out the cancer cells by suppuration. In a series of cases he described a positive reaction by the death of cancer cells through various methods like absorption, extrusion, inflammation, and suppuration. However, further research failed to reproduce or substantiate his postulations. At the XII Congress for Internal Medicine at Wiesbaden, Adamkiewicz demonstrated microscopic preparations validating these points, but he could not substantiate the same, and subsequent clinical trials failed to demonstrate these postulates conclusively. Adamkiewicz's work was met with severe criticism from the scientific 


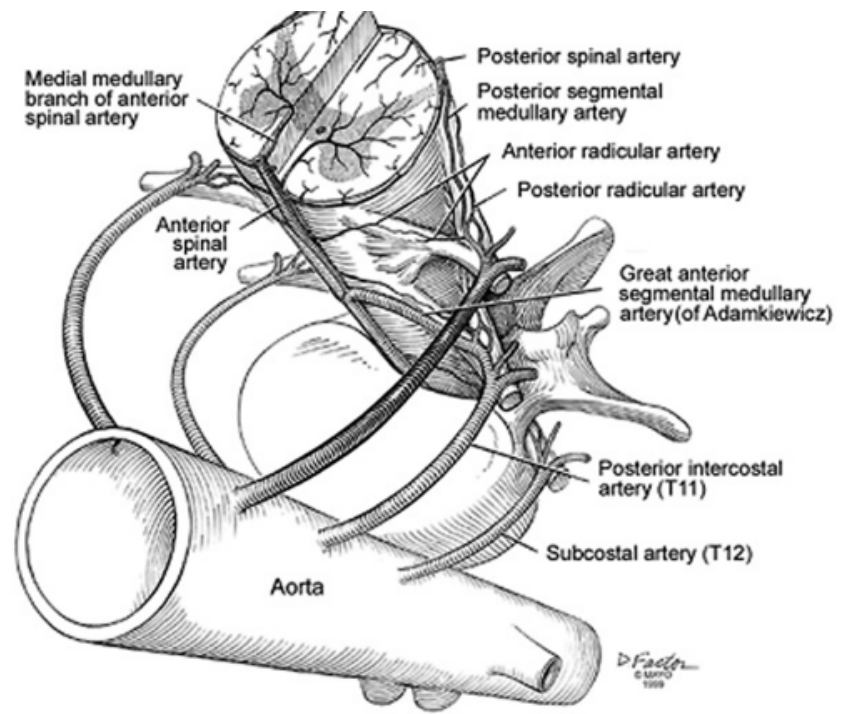

FIG. 5. Drawing demonstrating blood supply of the spinal cord and its anatomical relations, as well as the origin and course of the artery of Adamkiewicz.

community, especially the faculty of Jagiellonian University, which eventually made him retire temporarily from research. ${ }^{36}$

\section{Understanding the Anatomy of the Adamkiewicz Artery}

The spinal cord is supplied by 3 main vessels -1 anterior and 2 posterior spinal arteries-all of which run a longitudinal course along the spinal cord. The ASA originates as 2 roots from both vertebral arteries and unites to form a single artery, which courses along the anterior midline of the spinal cord, supplying $75 \%$ of the spinal cord in the anterior region. The 2 posterior arteries also arise from the vertebral artery, run along the posterolateral sulci of the spinal cord, and supply the posterior $25 \%$ of the spinal cord. An arteriolar-sized vessel encircles the spinal cord and undergoes limited anastomoses forming a fine network of blood vessels called the "vasocorona," which was originally described by Adamkiewicz. This skeleton structure of the main blood vessel network is supplied by radicular branches that enter through the intervertebral foramina. Adamkiewicz described 3 distinct spinal cord vascular zones along the length of the spinal cord. This description was confirmed in later years by further studies. The first segment extends up to the third thoracic segment and is supplied by branches of the subclavian artery. The second sector includes segments from T-1 to T-7 and is supplied by a single artery at the fourth segment. The third sector includes the area from T-8 to the end of the spinal cord supplied by the Adamkiewicz artery. In short, the cervical region of the spinal cord receives blood from vertebral, posterior inferior cerebellar, and segmental arteries. While the thoracic region receives blood supply from the anterior and posterior radicular branches of the dorsal branch of the posterior intercostal artery, the lower two-thirds of the spinal cord is enriched by blood supply from the artery of Adamkiewicz. There are on average 8 anterior medullary and 12 posterior medullary feeding arteries (Fig. 5).

The Adamkiewicz artery most often forms the sole source of blood supply to the lower segment of the spinal cord. ${ }^{34}$ For this reason the knowledge of variation in the artery of Adamkiewicz has assumed prime surgical importance. The artery of Adamkiewicz originates from intercostal or lumbar arteries and measures $\sim 2.5 \mathrm{~cm}$ in length from the spinal dura mater to the medulla. After its entry the artery courses inferiorly for nearly $15 \mathrm{~cm}$. Splits are found in the descending branch of the artery, which points toward the hypothesis of a double embryological source. ${ }^{28,35}$ The level and side of origin of the artery of Adamkiewicz have been described by various authors of clinical and pathological studies. Based on the level of origin, 2 presentations have been described: a high presentation where the artery originates from above the T-10 level and a low presentation where it originates from below T-10. ${ }^{18}$ Lazorthes et al. ${ }^{18}$ have noted a T9-12 origin in $74 \%$ of cases, between T-5 and T-8 in 15\%, and from L-1 to L-2 in $10 \%$. Alleyne et al. ${ }^{1}$ have reported a left-sided origin in $78 \%$ of cases and an origin branching from T-9 to T-12 in $60 \%$ of cases, from L-1 in 25\%, and from T- 5 to $\mathrm{T}-8$ in $15 \%$. The left-sided predominance was most probably due to an aorta located on the left side. Very rarely, a lower-segment origin, as low as the L-4 level, has been reported..$^{19}$ The average diameter of the artery of Adamkiewicz was found to be $0.9 \mathrm{~mm}$ (range $0.6-1.2 \mathrm{~mm}$ ) by Rodriguez-Baeza et al., ${ }^{28}$ and this finding was in agreement with data reported by Alleyne et al. (average 0.92 $\mathrm{mm}$, range $0.7-1.2 \mathrm{~mm}){ }^{1}$ Alleyne et al. have also noted the relationship of the artery of Adamkiewicz to the nerve root foramen and the dorsal root ganglion-ventral ganglion complex. The artery of Adamkiewicz was noted at the rostral or middle portion of the foramen, ventral and slightly rostrolateral to the ganglion complex. Moreover, the intradural portion of the artery of Adamkiewicz proximal to the junction with the ASA was consistently devoid of branches.

The variations in the anatomy of the ASA also have profound influence on maintaining the blood supply of the spinal cord. The first variation described is a welldeveloped ASA that originates in the upper cervical segment and courses downward with good patency and receives supply from the radicular arteries and the artery of Adamkiewicz. In a second type of variation the ASA is poorly formed at places, and regions of the spinal cord have the potential for ischemia. The third, most dangerous, and rarest ASA structure includes a very poorly developed artery, which in mostly thoracic regions is so poorly formed that it loses its continuity; this system is termed the "risk system." The latter described structure is associated with the highest risk of paraplegia. ${ }^{30}$ Postoperative paraplegia can result from the disruption of the artery of Adamkiewicz. An absent or decreased blood flow in the spinal cord area supplied by the artery of Adamkiewicz causes colonic ischemia, sensory deficits, loss of bowel and bladder control, and the worst case scenario for paraplegia. ${ }^{22}$

A wide spectrum of events can lead to a disruption 


\section{S. Manjila et al.}

in blood supply to the spinal cord via the artery of Adamkiewicz, such as a direct arterial insult (for example, rupture of an arteriovenous malformation), intraoperative clamping or ligation, and arterial dissection during trauma and reconstructive surgeries. Aneurysms of the artery of Adamkiewicz per se may be rare, but complications such as the rupture of these aneurysms during pregnancy have been reported. ${ }^{8}$ There have been anecdotal cases of embolism in the artery of Adamkiewicz during coronary artery bypass grafting or the removal of a nephroblastoma, or spasm of the artery due to perirenal abscess following percutaneous nephrolithotripsy, or of ischemic injury after oesophagectomy. ${ }^{6,27}$ Spasm of the artery of Adamkiewicz associated with umbilical artery catheterization has been reported by Munoz et al. ${ }^{23}$ The artery of Adamkiewicz has become a landmark in genitourinary laparoscopy, and its injury during retroperitoneal surgery has caused major catastrophic events leading to spinal cord dysfunction. Several methods have been used in the microsurgical repair of vascular malformations involving the spinal vasculature. Some early authors advocated reanastomosis of the feeder vessels to reduce the incidence of spinal cord ischemia.,12,32 The feasibility of extraanatomical revascularization of the artery of Adamkiewicz by using thoracic wall arteries has also been tested. ${ }^{21}$ There are different schools of thought regarding the need to identify and preserve the artery of Adamkiewicz and other radicular arteries during the operation. It is important to note that Fried et al. ${ }^{7}$ have demonstrated that the artery of Adamkiewicz could be ligated in rhesus monkeys without complications, but paraplegia resulted from the simultaneous blockage of the ASA. In 1969 these authors experimentally proved in monkeys that ligation of the Adamkiewicz artery did not impair spinal cord blood supply. These results point to the varied pattern of spinal cord vasculature and the need for intensive electrophysiological monitoring during surgery in this region.

Preservation of this artery during the endovascular management of spinal arteriovenous malformations with the aid of selective spinal angiography, as well as during endovascular stenting of an aortic aneurysm, has resulted from a logical approach to the treatment of these uncommon disorders. The high variability in the artery of Adamkiewicz presents a challenge in correctly identifying the artery. Imaging studies have been the backbone of preoperative identification of the artery of Adamkiewicz. Selective spinal angiography has been used extensively but is a time-consuming process, requires skilled hands, and often produces altered results in conditions such as aortic dissection or aneurysm, posing a greater risk of spinal cord injury. Magnetic resonance angiography has been extensively studied for identifying this artery noninvasively and reportedly has a better detection rate than selective angiography. The detection rate of selective arterial angiography is $43-86 \%,{ }^{10,16,29,39}$ that of MR angiography is $67-93 \%$, and that of CT angiography is $68-93 \% .13,15,17,33,40,42$ Yamada et al. ${ }^{40}$ have described the imaging criteria for identifying the artery of Adamkiewicz: a vessel that ascends to the anterior midsagittal surface of the cord, is a branch of the radiculomedullary artery, and usually originates from the dorsal branch of the intercostal or lumbar artery. This continuity of the vessel in the early phase of contrast MR angiography was the most reliable criterion; the second most reliable criterion was the reduced signal intensity in the late phase. The hairpin turn of the connection of the artery of Adamkiewicz to the ASA also helps with identification in the early phase. $^{14}$

Hyodoh and colleagues ${ }^{13,14}$ have used the method of double subtraction angiography to enhance the visualization of the artery of Adamkiewicz. In the method described by Watanabe et al., ${ }^{38}$ they used precontrast imaging with repeated sequences after giving a bolus contrast injection. After subtraction of the pre-contrast phase images from a subsequent set of images, they obtained arterial, arterioportal, and arteriovenous phase images. Subsequent subtraction of the arterial phase from the arteriovenous phase images enabled them to demonstrate veins and arteries separately and clearly. Multidetector row CT was also tried in identifying the artery of Adamkiewicz, and this modality could provide a 3D view, was faster than MR angiography, and could better identify branches of the artery. However, it also had the disadvantage that the anterior radicular vein was difficult to differentiate and that the contrast agent used had a significant adverse effect on kidneys. One major disadvantage of an imaging study alone is the failure to detect the artery of Adamkiewicz because of conditions such as occlusion of the orifice by atherosclerotic changes or other processes. ${ }^{41}$

The extent of viable vascular anastomoses and their contribution to spinal cord circulation cannot be judged by imaging studies alone. Another means of increasing artery identification and reducing postoperative morbidity is the concomitant use of intraoperative MEPs. With this method MEPs were monitored every 2-5 minutes during surgery, and if any procedure lowered the MEP amplitude to $<25 \%$ of its baseline, then potential ischemia of the spinal cord was considered to have occurred. This method significantly decreased the chance of postoperative complications. ${ }^{24}$

In an interesting study, Griepp et al. ${ }^{9}$ used somatosensory evoked potentials during surgery for aneurysms of the descending thoracic or thoracoabdominal aorta. These authors used average signals of 200 potentials, which were cycled between the 2 ankles in an area overlying the posterior tibial nerves, and then the potentials were recorded from the scalp by using multiple skin electrodes. They maintained adequate systemic blood pressure even when the intercostal arteries were being sacrificed. An idea that evolved further was if blood pressure is maintained in the descending aorta by the timely management of bleeding, then collateral vessels will take over and adequate perfusion will be maintained. If necessary, the intercostal arteries, which may have been sources of bleeding, were removed or completely obliterated to sustain blood pressure and prevent a "steal phenomenon" by the ASA. Similar case series have been described in 2 other major studies..$^{2,3}$ The combination of intraoperative somatosensory evoked potentials and postoperative care and caution showed positive outcomes in the study by Griepp and colleagues. ${ }^{9}$ This result led the authors to assert that it is better and more rewarding to devote more attention to 
preoperative planning to minimize injury and maximize cord circulation, rather than struggle to delineate and preserve the artery of Adamkiewicz during surgery.

Just as with the imaging techniques, chemical test occlusion of the artery of Adamkiewicz has been tried during surgery. Luyendijk et al. ${ }^{20}$ have described a unique method of identifying territory supplied by the artery of Adamkiewicz before performing surgery on an intramedullary astrocytoma extending downward from the T-12 segment. They injected the anesthetic agent etomidate selectively into the great radicular artery, which caused medullary dysfunction from the T-10 cord level downward. The authors postulated that this technique could be used to study the territory of the artery of Adamkiewicz. In a similar study, the significance of collateral vessels was also well shown. The authors removed a large aneurysm, which was lying in front of the spinal cord at the T-8 level, after clipping both ends of the ASA and the medullary supply. The patient recovered from complete paraplegia, which indicates that collateral vessels had developed in the hypoperfused area. There are not enough published data on pharmacological stress testing in surgery involving the artery of Adamkiewicz.

\section{Conclusions}

The anatomical discovery made more than a century ago by Albert Adamkiewicz continues to exert significant influence in several subspecialties of modern medicine. The contributions of this prominent neuropathologist, apart from the eponymic artery, have been discussed while highlighting his research on tissue staining and neoplasms. His invaluable pioneering work on spinal cord vasculature will be debated and forever honored by the medical fraternity. Identifying the exact location, origin, and nature of the artery of Adamkiewicz will help in reducing postoperative morbidity and death in spinal cord surgery and aortic aneurysm surgery. Extensive, dedicated clinical research must be done in areas such as noninvasive imaging of human spinal cord vascularization as well as pharmacological stress testing to make microsurgery and endovascular procedures for spinal cord lesions safe and efficacious.

\section{References}

1. Alleyne CH, Cawley CM, Shengelaia GG, Barrow DL: Microsurgical anatomy of Artery of Adamkiewicz and its segmental artery. J Neurosurg 89:791-795, 1998

2. Acher CW, Wynn MM, Hoch JR, Popic P, Archibald J, Turnipseed WD: Combined use of cerebrospinal fluid drainage and naloxone reduces the risk of paraplegia in thoracoabdominal aneurysm repair. J Vasc Surg 19:236-246, 1994

3. Borst HG, Laas J: Risk of replacement of descending aorta with a standardized left heart bypass technique. J Thorac Cardiovasc Surg 107:126-133, 1994

4. Cech P: Nazwisko Adamkiewicza w slownictwie medycznym w ostatnich trzech dekadach XX wieku. [The name of Adamkiewicz in medical archives in the last three decades of the 20th century.] Arch Hist Filoz Med 64:297-316, 2001

5. Crawford ES, Svensson LG, Hess KR, Shenaq SS, Coselli JS, Safi HJ, et al: A prospective randomized study of cerebrospinal fluid drainage to prevent paraplegia after high-risk sur- gery on the thoracoabdominal aorta. J Vasc Surg 13:36-45, 1991

6. Djurberg H, Haddad M: Anterior spinal artery syndrome. Paraplegia following segmental ischaemic injury to the spinal cord after oesophagectomy. Anaesthesia 50:345-348, 1995

7. Fried LC, DiChiro G, Doppman JL: Ligation of major thoracolumbar spinal cord arteries in monkeys. J Neurosurg 31:608-614, 1969

8. Garcia CA, Stella Dulcey, Jose Dulcey: Ruptured aneurysm of spinal Artery of Adamkiewicz during pregnancy. Neurology 29:394-398, 1979

9. Griepp RB, Ergin MA, Galla JD, Lansman S, Khan N, Quintana C, et al: Looking for Artery of Adamkiewicz: Aquest to minimize paraplegia after operations for aneurysms of the decending thoracic and thoracoabdominal aorta. J Thorac Cardiovasc Surg 112:1202-1215, 1996

10. Heinemann MK, Brassel F, Herzog T, Dresler C, Becker H, Borst HG: The role of spinal angiography in operation on the thoracic aorta: myth or reality? Ann Thorac Surg 65:346351, 1998

11. Herman E: Albert Wojciech Adamkiewicz(11.VIII.-31.X.1921). Neuropatol Pol 6:1-10, 1968

12. Hollier LH, Money SR, Naslund TC, Proctor CD Sr, Buhrman WC, Marino RJ, et al: Risk of spinal cord dysfunction in patients undergoing thoracoabdominal aortic replacement. Am J Surg 164:210-214, 1992

13. Hyodoh H, Kawaharada N, Akiba H, Tamakawa M, Hyodoh K, Fukada J, et al: Usefulness of preoperative detection of Artery of Adamkiewicz with dynamic contrast enhanced MR angiography.: Radiology 236:1004-1009, 2005

14. Hyodoh H, Shirase R, Akiba H, Tamakawa M, Hyodoh K, Yama N, et al: Double subtraction maximum intensity projection MR angiography for detecting the artery of Adamkiewicz and differentiating it from the drainage vein. J Magn Reson Imaging 26:359-365, 2007

15. Kawaharada N, Morishita K, Hyodoh H, Fujisawa Y, Fukada J, Hachiro Y, et al: Magnetic resonance localization of the Artery of Adamkiewicz for spinal cord blood supply. Ann Thorac Surg 78:846-852, 2004

16. Kieffer E, Fukui S, Chiras J, Koskas F, Bahnini A, Cormier E: Spinal cord arteriography: a safe adjunct before descending thorcic or thoracoabdominal aortic aneurysectomy. J Vasc Surg 25:262-268, 2002

17. Kudo K, Terae S, Asano T, Oka M, Kaneko K, Ushikoshi S, et al.: Anterior spinal artery and Artery of Adamkiewicz detected using multi-detector row CT. AJNR AM J Neuroradiol 24: 13-17, 2003.

18. Lazorthes G, Poulhes J, Bastide G, Chan CA, Zade H: [Vasculature of the spinal cord: anatomical and physiological study.] Rev Neurol 106:535-557, 1962 (Fr)

19. Lo D, Valee JN, Spelle L, Cormier E, Saillant G, Rancurel G, et al: Unusual origin of artery of Adamkiewicz from fourth lumbar artery. Neuroradiology 44:153-157, 2002

20. Luyendijk W, Cohn B, Rejger V, Vielvoye GJ: The great radicular artery of Adamkiewicz in man. Demonstration of a possibility to predict its functional territory. Acta Neurochir (Wien) 95:143-146, 1988

21. Malikov S, Rosset E, Paraskevas N, Magnan PE, Poirier M, Bartoli JM, et al: Extraanatomical revascularization of the artery of Adamkiewicz: anatomical study. Ann Vasc Surg 16:723-729, 2002

22. Milen MT, Bloom DA, Culligan J, Murasko K: Albert Adamkiewicz (1850-1921) - his artery and its significance for the retroperitoneal surgeon. World J Urol 17:168-170, 1999

23. Munoz ME, Roche C, Escriba R, Martínez-Bermejo A, Pascual-Castroviejo I: Flaccid paraplegia as complication of umbilical artery catheterization. Pediatr Neurol 9:401-403, 1993 


\section{S. Manjila et al.}

24. Ogino H, Sasaki H, Minatoya K, Matsuda H, Yamada N, Kitamura S: Combined use of Adamkiewicz artery demonstration and motor-evoked potentials in descending and thoracoabdominal repair. Ann Thorac Surg 82:592-596, 2006

25. Operacz H, Swiderski G, Operacz R, Swiderska K: [The life of Albert Wojciech Adamkiewicz-part I.] Chir Narzadow Ruchu Ortop Pol 60:419-422, 1995 (Polish)

26. Pawlina W, Maciejewska I: Albert Wojciech Adamkiewicz 1850-1921. Clin Anat 15:318-320, 2002

27. Pellegrinelli M, Castiglioni C, Morini O, Franzini A: Spastic paraparesis as a complication of percutaneous nephrolithotripsy (PNL) on a calyceal calculus of the left kidney. Arch Ital Urol Androl 79:147-150, 2007

28. Rodriguez-Baeza A, Muset-Lara A, Rodriguez-Pazos M, Domenech-Mateu JM: The arterial supply of human spinal cord: a new approach to the arteria radicularis magna of Adamkiewicz. Acta Neurochir (Wien) 109:57-62, 1991

29. Savader SJ, William GM, Trerotola SO, Perler BA, Wang MC, Venbrux AC, et al: Preoperative spinal artery localization and its relationship to post operative neurologic complication. Radiology 189:165-171, 1993

30. Skalski JH, Zembala M: Albert Wojciech Adamkiewicz: the discoverer of the variable vascularity of the spinal cord. Ann Thorac Surg 80:1971-1975, 2005

31. Sokolowska-Pituchowa J: Two monographs on the spinal cord vascularization. Folia Morphol (Warsz) 39:1-8, 1980

32. Svensson LG: Intra operative identification of spinal cord blood supply during repairs of descending aorta and thoracoabdominal aorta. J Thorac Cardiovasc Surg 112:14551461,1996

33. Takase K, Sawamura Y, Igarashi K, Chiba Y, Haga K, Saito H, et al: Demonstration of artery of Adamkiewicz at multi detector row helical CT. Radiology 223:39-45, 2002

34. Tanon L: Le arteres de lamoelle dorso-lombaire. Considerations anatomiques et cliniques. Paris: Vigot Freres, 1908
35. Torr JBD: The blood supply of human spinal cord. Thesis for doctorate of medicine. University of Manchester, 1957

36. Travis AH: Report on pathology and practical medicine: Adamkiewicz on cancer. Epitome Med 189:405, 1893

37. Wachholz L: Polski Slownik Biograficzny, Adamkiewicz Albert. Poland: Akad Umiej, 1935

38. Watanabe Y, Dohke M, Okumura A, Amoh Y, Ishimori T, Oda $\mathrm{K}$, et al: Dynamic subtraction contrast-enhanced MR angiography: technique, clinical applications and pitfalls. Radiographics 20:135-153, 2000

39. Williams GM, Roseborough GS, Webb TH, Perler BA, Krosnick T: Preoperative selective intercostal angiography in patients undergoing thoracic aneurysm repair. J Vasc Surg 39:314-321, 2004

40. Yamada N, Takamiya M, Kuribayashi S, Okita Y, Minatoya K, Tanaka R: MRA of the Ademkiewicz artery: a pre operative study for thoracic aortic aneurysm. J Comput Assist Tomogr 24:362-368, 2000

41. Yoshioka K, Niinuma H, Ehara S, Nakajima T, Nakamura M, Kawazoe K: MR angiography and CT angiography of artery of Adamkiewicz: state of the art. Radiographics 26:S63-S73, 2006

42. Yoshioka K, Niinuma H, Ohira A, Nasu K, Kawakami T, Sasaki M, et al: MR angiography and CT angiography of artery of Adamkiewicz: noninvasive preoperative assesment of thoracoabdominal aneurysm. Radiographics 23:1215-1225, 2003

Manuscript submitted September 15, 2003.

Accepted October 23, 2008.

Address correspondence to: Setti S. Rengachary, M.D., 4160 John R Street, Suite 930, Detroit, Michigan 48201. email: srengachary@ yahoo.com. 